\title{
Aerosol single-scattering albedo and asymmetry parameter from MFRSR observations during the ARM Aerosol IOP 2003
}

\author{
E. I. Kassianov ${ }^{1}$, C. J. Flynn ${ }^{1}$, T. P. Ackerman ${ }^{2}$, and J. C. Barnard ${ }^{1}$ \\ ${ }^{1}$ Pacific Northwest National Laboratory, Richland, 99352, USA \\ ${ }^{2}$ University of Washington, Seattle, 98195, USA
}

Received: 30 October 2006 - Published in Atmos. Chem. Phys. Discuss.: 21 December 2006

Revised: 10 April 2007 - Accepted: 6 June 2007 - Published: 27 June 2007

\begin{abstract}
Multi-filter Rotating Shadowband Radiometers (MFRSRs) provide routine measurements of the aerosol optical depth $(\tau)$ at six wavelengths $(0.415,0.5,0.615,0.673$, 0.870 and $0.94 \mu \mathrm{m})$. The single-scattering albedo $\left(\varpi_{0}\right)$ is typically estimated from the MFRSR measurements by assuming the asymmetry parameter $(g)$. In most instances, however, it is not easy to set an appropriate value of $g$ due to its strong temporal and spatial variability. Here, we introduce and validate an updated version of our retrieval technique that allows one to estimate simultaneously $\varpi_{0}$ and $g$ for different types of aerosol. We use the aerosol and radiative properties obtained during the Atmospheric Radiation Measurement (ARM) Program's Aerosol Intensive Operational Period (IOP) to validate our retrieval in two ways. First, the MFRSR-retrieved optical properties are compared with those obtained from independent surface, Aerosol Robotic Network (AERONET), and aircraft measurements. The MFRSR-retrieved optical properties are in reasonable agreement with these independent measurements. Second, we perform radiative closure experiments using the MFRSR-retrieved optical properties. The calculated broadband values of the direct and diffuse fluxes are comparable $\left(\sim 5 \mathrm{~W} / \mathrm{m}^{2}\right)$ to those obtained from measurements.
\end{abstract}

\section{Introduction}

One of the key uncertainties in the Earth's radiation balance is the effect of aerosols on radiative fluxes, which in turn affects climatic processes on both planetary and local scales (e.g., Hansen et al., 1997; Zhang et al., 2005). Determination of the aerosol-induced radiative flux changes requires information about aerosol optical properties, such as the aerosol optical depth $(\tau)$, single-scattering albedo $\left(\varpi_{0}\right)$ and asym-

Correspondence to: E. I. Kassianov

(evgueni.kassianov@pnl.gov) metry parameter ( $g$ ) (e.g., Haywood and Shine, 1995; Russell et al., 1997; Andrews et al., 2006). The variation of $\varpi_{0}$ can modify not only the magnitude of the aerosol-induced change in top-of-atmosphere upwelling flux, but its sign as well (from a cooling to a heating aerosol effect). The critical value of $\varpi_{0}$, where cooling shifts to heating, depends on the surface albedo, $\tau$, and $g$.

Aerosol properties can be derived through in situ measurements (e.g., Sheridan et al., 2001; Andrews et al., 2004). Commonly, $\varpi_{0}$ is estimated from scattering and absorption coefficients measured by an integrating nephelometer and a particle soot absorbance photometer (PSAP), respectively. The asymmetry parameter can be obtained by using measured backscatter fraction (ratio of light scattered into the backward hemisphere to total light scattering) and an appropriate parameterization (e.g., Wiscombe and Grams, 1976). An alternative approach for determining aerosol optical properties is to use combined sun and sky irradiance measurements (e.g., Dubovik et al., 2002; Ricchiazzi et al., 2006). Such measurements are provided by a sunphotometer at four specific wavelengths $(0.44,0.67,0.87$, and $1.02 \mu \mathrm{m})$ supported by the Aerosol Robotic Network (AERONET) program (http://aeronet.gsfc.nasa.gov/; Holben et al., 1998). This approach allows one to derive aerosol optical properties from size distributions and complex refractive indexes retrieved as part of the AERONET inversion algorithm. Gonzalez-Jorge and Ogren (1996) discussed the uncertainties of aerosol optical properties calculated using aerosol size distributions derived from multiwavelength optical depths.

Widely deployed Multi-filter Rotating Shadowband Radiometers (MFRSRs) measure values of the total and diffuse solar irradiances at six narrowband wavelength channels centered at $0.415,0.5,0.615,0.673,0.870$ and $0.94 \mu \mathrm{m}$. These quantities are used to obtain the direct solar irradiances, which in turn are applied to derive $\tau$ (Harrison and Michalsky, 1994; Alexandrov et al., 2002). To estimate $\varpi_{0}$,

Published by Copernicus Publications on behalf of the European Geosciences Union. 
the diffuse-to-direct ratio (DDR) is commonly used. Such estimation based on DDR was first outlined by Herman et al. (1975) and successfully applied in aerosol studies (e.g., Petters et al., 2003; Halthore et al., 2004; Meloni et al., 2006). An iterative process combining measurements of DDR with $\tau$, assumed surface albedo and $g$ is used to retrieve $\varpi_{0}$ at a given wavelength. The DDR-derived $\varpi_{0}$ values are sensitive to uncertainties/changes of $g$. For example, Meloni et al. (2006) demonstrated that \pm 0.06 variations of $g$ can produce $0.03-0.04$ changes of the DDR-derived $\varpi_{0}$ at $0.415 \mu \mathrm{m}$. Since $g$ is highly variable in space and time (Andrews et al., 2006), it is desirable to derive $g$ in addition to $\tau$ and $\varpi_{0}$ from MFRSR observations.

Previously, we proposed a simple retrieval technique that extends the capability of the MFRSR to study atmospheric aerosols (Kassianov et al., 2005). The technique allows one to estimate the microphysical (e.g., effective radius) and optical $\left(\varpi_{0}\right.$ and $g$ ) properties of aerosols. The retrieval is based on measurements of the direct irradiances at two wavelengths $(0.415 \mu \mathrm{m}$ and $0.870 \mu \mathrm{m})$ and the diffuse irradiance at $0.415 \mu \mathrm{m}$ and requires assumptions regarding the shape of the aerosol size distribution (e.g., a combination of three lognormal distributions), the real part of the refractive index, and an estimate of the surface albedo at $0.415 \mu \mathrm{m}$. This version works poorly for cases with weak spectral dependence of $\tau$ and was evaluated by using limited dataset (urban aerosol, single day). Thus, there is a need to increase the flexibility of the MFRSR retrieval and better understand its strengths and weaknesses by performing additional sensitivity studies and/or independent measurements.

In the next section, we describe an updated version of this technique that allows one to perform aerosol retrievals for key types of aerosols (e.g., different loading and spectral dependence of $\tau$ ) and its further validation using available ground-based and aircraft measurements during the Atmospheric Radiation Measurement (ARM) Program Aerosol Intensive Operational Period (IOP). In Sect. 3 of this paper, we review the ARM Aerosol IOP, describe different retrieval techniques, and highlight selected cases. Our MFRSR retrievals of aerosol optical properties are compared with independent retrievals in Sect. 4 . Section 5 contains the radiative closure results. In Sect. 6, we present a summary.

\section{Updated version of the MFRSR retrieval}

Our technique consists of two basic steps. The first step provides the aerosol size distribution. To do that, we iterate the parameters of the size distribution to match the spectral dependence of the aerosol optical depth. The second step estimates the imaginary part of the refractive index. To do that, we iterate values of the imaginary refractive index (for a given size distribution) to match the spectral dependence of the DDR. Below we discuss each step in detail.
For the first step, we assume that columnar size distribution of aerosol can be described by a combination of two lognormal distributions that represent fine (f) and coarse (c) modes (e.g., Dubovik et al., 2002)

$$
\begin{aligned}
\frac{d V(r)}{d \ln r}= & \frac{C_{f}}{\sqrt{2 \pi} \sigma_{f}} \exp \left[-\frac{\left(\ln r-\ln R_{f}\right)^{2}}{2 \sigma_{f}^{2}}\right] \\
& +\frac{C_{c}}{\sqrt{2 \pi} \sigma_{c}} \exp \left[-\frac{\left(\ln r-\ln R_{c}\right)^{2}}{2 \sigma_{c}^{2}}\right],
\end{aligned}
$$

where $r$ is particle radius, $C, R$ and $\sigma^{2}$ are the volume concentration, volume median particle radius and variance, respectively. By assuming that aerosol particles are homogeneous spheres, we can relate (through the Lorenz-Mie theory) the aerosol optical depth $\tau_{\lambda}$ with size distribution and complex refractive index $\tilde{m}_{\lambda}=m_{1, \lambda}+i m_{2, \lambda}$ as

$\tau_{\lambda}=\int_{r_{\min }}^{r_{\max }} n(r) K_{\mathrm{ext}, \lambda}\left(r, \tilde{m}_{\lambda}\right) d r$,

where $n(r)$ is columnar particle number size distribution, and $K_{\text {ext, } \lambda}$ is extinction cross sections. The particle number size distribution is linked with the volume size distribution as $n(r) r\left(4 / 3 \pi r^{3}\right)=d V(r) / d \ln r$. To estimate the size distribution from Eqs. (1) and (2), we make two additional assumptions: (1) the refractive index $\tilde{m}_{\lambda}$ is known, and (2) the variances $\left(\sigma_{f}^{2}, \sigma_{c}^{2}\right)$ are known. The typical values and range of $\tilde{m}_{\lambda}$ and variances can be specified from the available AERONET dataset for different aerosols (e.g., Dubovik et al., 2002). It is important to note that the aerosol optical depth $\tau_{\lambda}$ is not sensitive to the imaginary refractive index $m_{2, \lambda}$ (King et al., 1978), thus for this step, the value chosen for $m_{2, \lambda}$ is not critical.

With these assumptions, we have four unknowns $\left(C_{f}, R_{f}\right.$; $\left.C_{c}, R_{c}\right)$. To estimate them, we have five constraints: the observed optical depth $\tau_{\mathrm{obs}, \lambda}$ at five wavelengths $(0.415,0.5$, $0.615,0.673,0.870 \mu \mathrm{m})$. Four parameters $\left(C_{f}, R_{f}, C_{c}, R_{c}\right)$ are determened using a minimization scheme. Values of these parameters that produce a minimum of the root-mean square error between model $\tau_{\bmod , \lambda}$ and observed $\tau_{\mathrm{obs}, \lambda}$ aerosol optical depths at five wavelengths are considered the best estimate of their true values. This error is defined as a square root of the sum $\frac{1}{k} \sum_{i=1}^{k}\left(\tau_{\bmod , i}-\tau_{\mathrm{obs}, i}\right)^{2}$, where $k$ is the number of considered wavelengths, equal to 5 here. We expect that the size distribution derived in this manner, while not perfect, will at least be plausible. We validate this assertion in Sect. 4. To speed up the retrieval, we created look-up tables $\tau_{\bmod , \lambda}\left(C_{f}, R_{f} ; C_{c}, R_{c}\right)$ for a given $\tilde{m}_{\lambda}$. For the ARM Aerosol IOP, we set the complex refractive index as 1.5+0.007i. In look-up tables, parameters $C_{f}$ and $C_{c}$ range from 0.01 to $0.12\left(\mu \mathrm{m}^{3} / \mu \mathrm{m}^{2}\right)$; while $R_{f}$ and $R_{c}$ are varied through $(0.1-0.25 \mu \mathrm{m})$ and $(1-3 \mu \mathrm{m})$ ranges, respectively. 

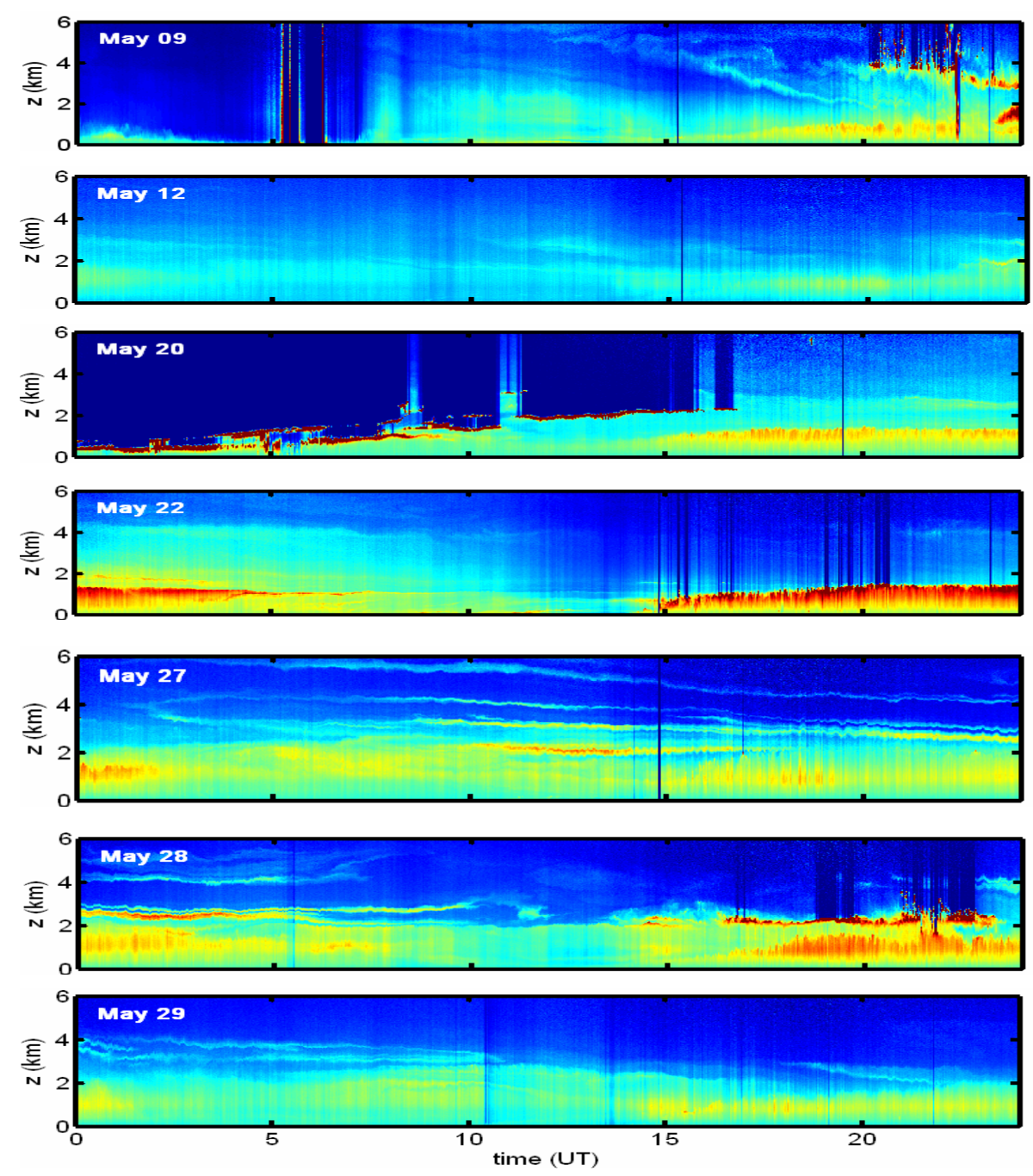

Fig. 1. Two-dimensional images of micropulse lidar backscatter for 9 May, 12 May, 20 May, 22 May, 27 May, 28 May and 29 May; horizontal axis - time (UT), vertical axis - altitude (km). Increasing color wavelength (blue to yellow to red) represents increasing backscatter.

The previous version described in Kassianov et al. (2005) estimates two bulk parameters (the zeroth and first moments of the three-modal size distribution) only. Replacing two fitting parameters by four fitting parameters in the updated version described here seems to provide reasonable size distributions (Sect. 4) that are not dependent on assumptions about the three modes required in the previous version. We emphasize that while the previous version made use of an iterative procedure to derive two bulk parameters, the updated version incorporates look-up tables, which is why the updated version runs faster than the original one. The updated version has been applied successfully to derive optical properties of dust during the major Saharan dust storm of March 2006 (Slingo et al., 2006).

The second step estimates the imaginary refractive index $m_{2, \lambda}$ using the observed spectral values of $\mathrm{DDR}_{\mathrm{obs}, \lambda}$ at five wavelengths $(0.415,0.5,0.615,0.673,0.870 \mu \mathrm{m})$. This step requires an additional assumption that the spectral values of surface albedo (at these wavelengths) are known. Given this assumption, we have a closed problem of five unknowns $\left(m_{2, \lambda}\right)$, and five knowns (DDR $\left.\operatorname{Dbs}_{2}\right)$. The second step involves the following sequence. We start with calculations of aerosol optical properties $\varpi_{0, \lambda}$ and $g_{\lambda}$ from Mie theory as function of $m_{2, \lambda}$ for the size distribution found in step one. Then we use aerosol optical properties $\left(\tau_{\lambda}, \varpi_{0, \lambda}, g_{\lambda}\right)$ to calculate the model DDR mod, $\lambda$ as function of $m_{2, \lambda}$. Finally, we iterate this sequence until the difference between model DDR mod, $\lambda$ and observed $\mathrm{DDR}_{\mathrm{obs}, \lambda}$ ratios is less than a given threshold (e.g., 5\%). It should be mentioned that $\mathrm{DDR}_{\lambda}$ is independent of the instrument calibration constant, extraterrestrial solar spectrum, stratospheric ozone, and nitrogen dioxide because the direct and diffuse components are measured by the same sensor and, therefore, these factors are the same for each wavelength irradiance pair. The updated 


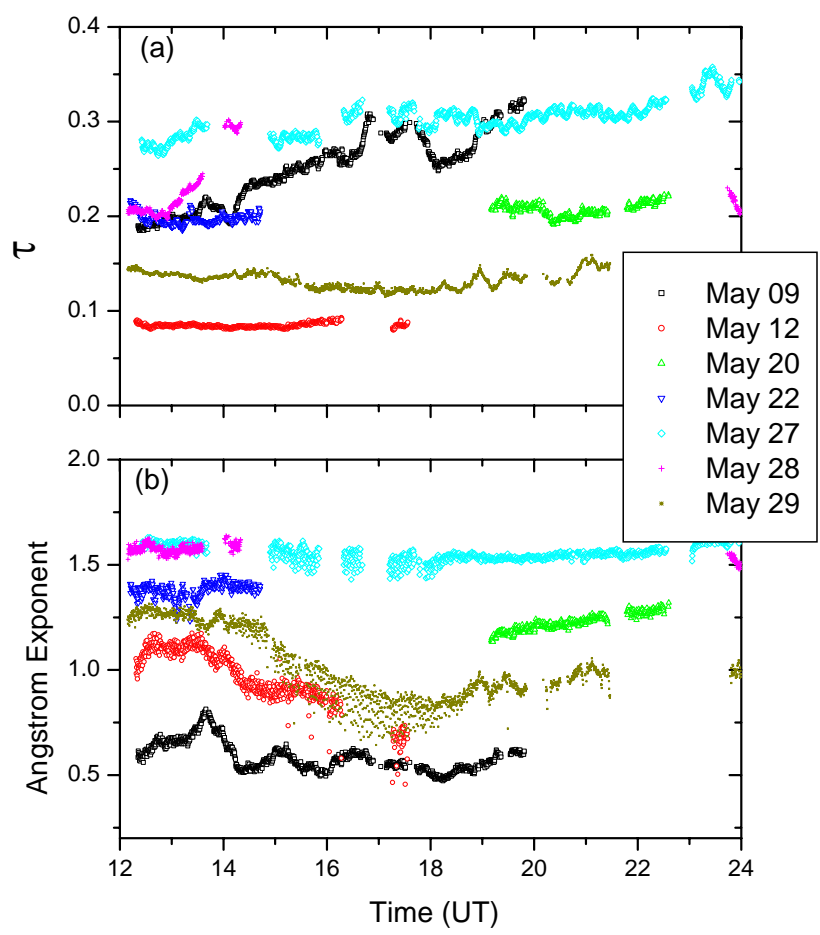

Fig. 2. Aerosol optical depth $(\tau)$ at $0.5 \mu \mathrm{m}$ (a) and Angstrom exponent $(0.5 / 0.87 \mu \mathrm{m})$ (b) derived from MFRSR data for selected 8 cases.

version of our retrieval incorporates a circumsolar correction for radiation scattered within the field-of-view $(\sim 3.3 \mathrm{de}-$ grees) of the MFRSR. Originally, this correction was introduced by Min et al. (2004) for estimating thin cloud optical depth of from MFRSR observations. Min et al. (2004) used a low order scattering approximation to compute radiance in forward direction. We used the same approach as was described in Min et al. (2004), except that the forward scattering is estimated by a Monte Carlo method. Such a correction can be important for low sun elevation angles, large aerosol loadings, and/or large particles sizes.

\section{Aerosol IOP and selected cases}

The Aerosol IOP was conducted from 5 through 31 May 2003, over the ARM Climate Research Facility (ACRF) Southern Great Plains (SGP) site. The Aerosol IOP yielded numerous cases studies spanning a wide range of aerosol situations including well mixed boundary layer cases, as well as cases with distinct elevated aerosol layers (Fig. 1), varying composition, loading and spectral dependence of $\tau$. Different meteorological conditions are responsible for such aerosol variability including several observed plumes (e.g., Ferrare et al., 2006; Strawa et al., 2006) from urban, industrial, or biomass burning sources (Wang et al., 2006; Gasparini et al., 2006). For example, model results and lidar retrievals suggest that the Central America smoke was transported to the ACRF SGP site on 9 May 2003 (Wang et al., 2006). According to the aircraft report, there are a few elevated aerosol layers with high and low absorption for this day. The selected cases are characterized by different aerosol loading (Fig. 2). The measured $\tau$ for 27 May is close to 0.3 $(0.5 \mu \mathrm{m})$, nearly three times larger than the corresponding $\tau$ for 12 May. Also, the Angstrom exponent, which commonly expresses the $\tau$ wavelength behavior, changes from 0.69 (9 May) to 1.59 (28 May) (Michalsky et al., 2006).

During the Aerosol IOP, the MFRSR observations were accompanied by independent in situ surface and aircraft observations (Table 1). Surface measurements of aerosol scattering and absorption coefficients, measured by a threewavelength nephelometer $(0.45,0.55$ and $0.7 \mu \mathrm{m})$ and onewavelength PSAP $(0.55 \mu \mathrm{m})$, are used to derive $\varpi_{0}$. These instruments are part of the Aerosol Observing System (AOS) (Sheridan et al., 2001). Uncertainties for $\varpi_{0}$ range from $2 \%$ to $7 \%$ for low- and high-absorbing aerosols (Strawa et al., 2003). These uncertainties are comparable with those obtained from AERONET data: about 0.03 and $0.05-0.07$ for typical $\left(\tau_{0.44}>0.2\right)$ and low $\left(\tau_{0.44} \leq 0.2\right)$ values of aerosol optical depth, respectively (Dubovik et al., 2002). The retrieval errors of AERONET-derived $g$ are in range of 3-5\% (Andrews et al., 2006). Commonly, $g$ is derived by using the hemispheric backscatter fraction and the parameterization (Wiscombe and Grams, 1976). Uncertainties for the hemispheric backscatter fraction lie between 0.012 and 0.018 (Sheridan et al., 2002). For $g$ values derived from backscatter fraction, uncertainties vary, on average, in the $3-4 \%$ range and can reach $14 \%$ for individual data points (Fiebig and Ogren, 2006). Andrews et al. (2006) provide a comprehensive overview of available methods for deriving $g$ and a detailed comparison between them. To take into account the hygroscopic growth of aerosol under ambient humidity conditions, the dry scattering coefficient (at instrumental relative humidity) is adjusted. The CIRPAS Twin Otter aircraft collected data during 15 days (between 6 and 29 May), mostly under clear or partly cloudy conditions. As with the surface observations, aircraft measurements of the aerosol scattering and absorption coefficients are measured by a nephelometer $(0.45,0.55$ and $0.7 \mu \mathrm{m})$ and PSAP $(0.55 \mu \mathrm{m})$ at different altitudes (z). Similar to Andrews et al. (2006), we determine the column-integrated values of $g$ by weighting the individual values of $g(z)$ with measured profiles of the scattering coefficient. We determine the column-integrated values of $\varpi_{0}$ by weighting the individual values of $\varpi_{0}(z)$ with measured profiles of the extinction coefficient.

In order to find comparable datasets (in situ, AERONET and MFRSR), the following two criteria are applied. First, both the aircraft and surface measurements must occur within the same 4-h time period. Since this still allows for a temporal difference between measurements, they may not be coincident in the strict sense. Second, the selected periods must be mostly hemispherically cloud free (hemispherical 
Table 1. List of key instruments used for obtaining microphysical, optical and radiative properties of aerosol.

\begin{tabular}{|c|c|c|c|}
\hline Acronym & Definition & Measurements (range) & Reference \\
\hline PCASP & $\begin{array}{l}\text { Passive Cavity Aerosol Spectrome- } \\
\text { ter Probe }{ }^{\mathrm{a}, \mathrm{b}}\end{array}$ & $\begin{array}{l}\text { Aerosol particle size distribution } \\
(0.1-3.1 \mu \mathrm{m})\end{array}$ & Jonsson et al. (1995) \\
\hline CAPS & $\begin{array}{l}\text { Cloud, Aerosol and Precipitation } \\
\text { Spectrometer system }^{\mathrm{a}}\end{array}$ & $\begin{array}{l}\text { Particle size distribution } \\
(0.63-63.3 \mu \mathrm{m})\end{array}$ & Baumgardner et al. (2002) \\
\hline N/A & Nephelometer ${ }^{\mathrm{a}, \mathrm{b}}$ & $\begin{array}{l}\text { Aerosol scattering coefficient } \\
\text { Aerosol backscattering fraction } \\
(0.45,0.55 \text { and } 0.70 \mu \mathrm{m})\end{array}$ & Anderson and Ogren (1998) \\
\hline PSAP & $\begin{array}{l}\text { Particle Soot Absorption } \\
\text { Photometer }^{\mathrm{a}, \mathrm{b}}\end{array}$ & $\begin{array}{l}\text { Aerosol absorption coefficient } \\
(0.55 \mu \mathrm{m})\end{array}$ & Horvath (1993) \\
\hline MPL & Micropulse Lidar ${ }^{c}$ & $\begin{array}{l}\text { Vertical profiles of aerosol, } \\
\text { altitude of clouds } \\
(0.523 \mu \mathrm{m})\end{array}$ & Campbell et al. (2002) \\
\hline SKYRAD & $\begin{array}{l}\text { Sky radiation collection of } \\
\text { radiometers }\end{array}$ & $\begin{array}{l}\text { Direct and diffuse irradiances } \\
\text { (broadband shortwave) }\end{array}$ & http://www.arm.gov/instruments \\
\hline MFRSR & $\begin{array}{l}\text { Multi-filter Rotating Shadowband } \\
\text { Radiometer }^{c}\end{array}$ & $\begin{array}{l}\text { Total and diffuse solar irradiances } \\
(0.415,0.5,0.615,0.673,0.87,0.94 \mu \mathrm{m})\end{array}$ & Harrison and Michalsky (1994) \\
\hline NIMFR & $\begin{array}{l}\text { Normal Incidence Multifilter } \\
\text { Radiometer }^{\mathrm{c}}\end{array}$ & $\begin{array}{l}\text { Direct beam solar irradiance } \\
(0.415,0.5,0.615,0.673,0.87 \mu \mathrm{m})\end{array}$ & \\
\hline CIMEL & $\begin{array}{l}\text { Sun photometer, } \\
\text { Aerosol Robotic } \\
(\text { AERONET) })^{\mathrm{c}}\end{array}$ & $\begin{array}{l}\text { Sun and sky irradiance } \\
(0.44,0.67,0.87,1.02 \mu \mathrm{m})\end{array}$ & Holben et al. (1998) \\
\hline
\end{tabular}

${ }^{a}$ Aerosol Observing System (AOS), ${ }^{b}$ Twin Otter aircraft, ${ }^{c}$ At the surface

Table 2. Day and time (UTC) for surface, AERONET, and aircraft measurements for eight selected cases.

\begin{tabular}{lllll}
\hline & & \multicolumn{3}{c}{ Time } \\
\cline { 3 - 5 } Case & Day & Surface & AERONET & Aircraft \\
\hline 1 & 9 May & $17: 30$ & $17: 28: 30$ & $15: 28-20: 10$ \\
2 & 12 May & $15: 50$ & $17: 28: 27$ & $14: 48-19: 09$ \\
3 & 20 May & $20: 00$ & $20: 28: 31$ & $14: 49-18: 27$ \\
4 & 22 May & $14: 00$ & $17: 28: 45$ & $08: 25-13: 13$ \\
5 & 27 May & $19: 00$ & $19: 29: 16$ & $14: 20-19: 29$ \\
6 & 28 May & $24: 00$ & $20: 29: 20$ & $18: 24-22: 05$ \\
7 & 29 May & $14: 30$ & $16: 29: 30$ & $14: 11-17: 51$ \\
8 & 29 May & $18: 30$ & $17: 29: 33$ & $14: 11-17: 51$ \\
\hline
\end{tabular}

fractional sky cover $\leq 0.01)$. For this selection, we define a "hemispherically cloud free period" as determined by the algorithm of Long and Ackerman (2000). Eight cases are identified (Table 2). A ground-based CIMEL sun-sky scanning radiometer (part of AERONET) estimates aerosol microphysical and optical properties (e.g., Dubovik et al., 2002). For our comparison we use available cloud-screened data (level 1.5). The CIMEL radiometer was collocated with the AOS, the MFRSR and a normal incidence multifilter radiometer (NIMFR) to within a few hundred meters. Michal-

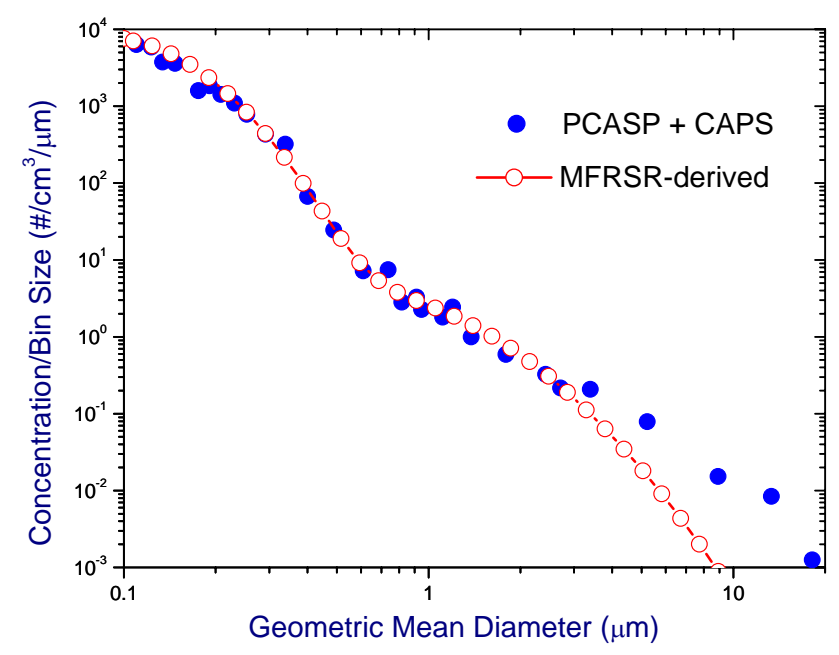

Fig. 3. Typical size distribution from sizing probes aboard the Twin Otter, the PCASP and CAPS (adapted from Hallar et al., 2006) (blue), and corresponding size distribution derived from MFRSR data (red) for 9 May 2003. The columnar MFRSR-derived size distribution is normalized (vertical shifting) to produce similar concentration for fine mode (geometric mean diameter is less than $1 \mu \mathrm{m}$ ).

sky et al. (2006) have shown that bias between the CIMELderived and the NIMFR-derived $\tau$ values was negligible. Biases between the MFRSR-derived and the NIMFR-derived 
Table 3. Root-mean-square error (RMSE) and R-squared value calculated for aerosol optical depth at wavelengths $(0.50 \mu \mathrm{m}$ and $0.87 \mu \mathrm{m})$ by using NIMFR, CIMEL and MFRSR data.

\begin{tabular}{lcccc}
\hline Wavelength & \multicolumn{2}{c}{ RMSE } & \multicolumn{2}{c}{$\mathrm{R}$} \\
\hline & NIMFR vs. CIMEL & NIMFR vs. MFRSR & NIMFR vs. CIMEL & NIMFR vs. MFRSR \\
\hline $0.50 \mu \mathrm{m}$ & 0.0075 & 0.0062 & 0.993 & 0.994 \\
$0.87 \mu \mathrm{m}$ & 0.0043 & 0.0046 & 0.993 & 0.989 \\
\hline
\end{tabular}
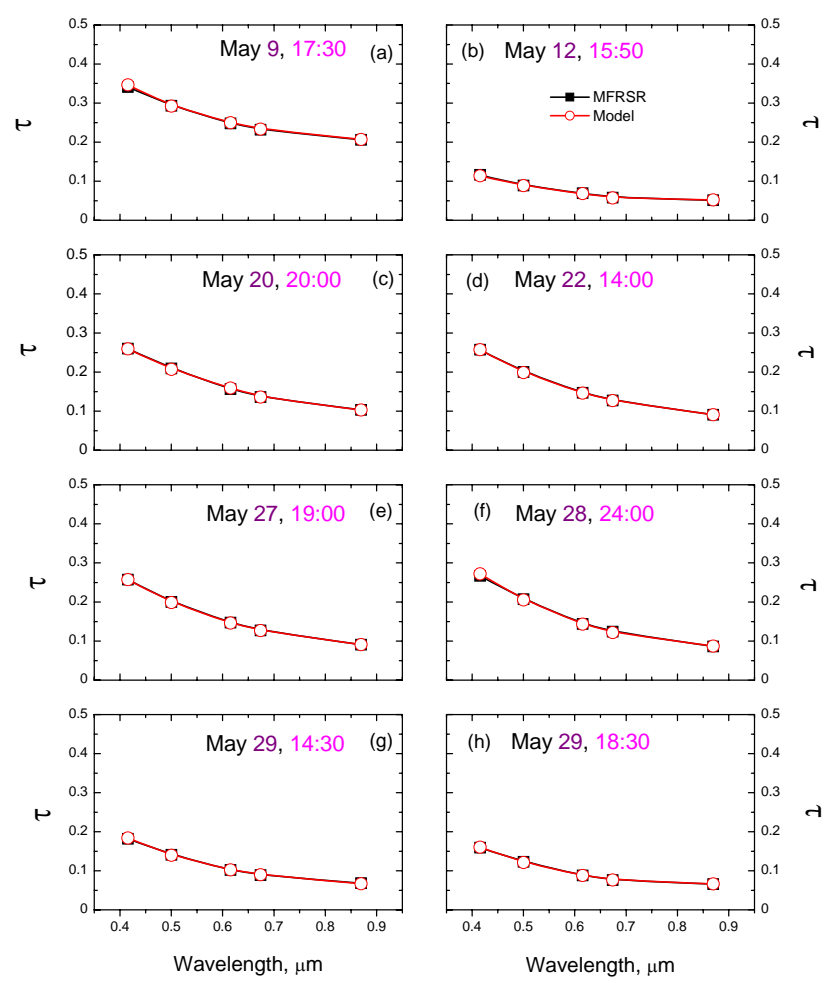

Fig. 4. The spectral dependence of the aerosol optical depth $\tau_{\lambda}$ for selected cases: $\tau_{\lambda}$ derived from the MFRSR data (square) and $\tau_{\lambda}$ obtained from Lorenz-Mie calculations (circle) by using the derived aerosol size distribution and refractive index.

$\tau$ values are also small (Table 3 ) for the time period of the aerosol IOP. The uncertainty of $\tau$ can affect substantially the model DDR (e.g., Ricchiazzi et al., 2006) and, thus, the retrieved values of $\varpi_{0}$ and $g$. Small variations of $\tau( \pm 0.01)$ can produce noticeable changes $( \pm 0.02)$ in $\varpi_{0}$ and $g$ (Appendix A). Smaller changes $( \pm 0.01)$ in $\varpi_{0}$ and $g$ can be associated with assumptions of variances (fine and coarse modes of size distribution) (Appendix B). Thus, the total uncertainties in the MFRSR-derived values of $\varpi_{0}$ and $g$ are about $\pm 0.03-0.04$. These uncertainties are similar to those that correspond to the AERONET and in situ measurements.

For all MFRSR retrievals, we assume that the shape of the aerosol volume size distribution is described by a com- bination of two lognormal distributions (e.g., Dubovik et al., 2002). This combined distribution has six parameters. We assume that the variances (widths) of fine and coarse modes are equal to 0.5 and 0.7 , respectively. Note that the retrieved variances ranged from 0.4 to 0.6 (fine mode) and from 0.6 to 0.8 (coarse mode) for typical aerosols (Dubovik et al., 2002), and the MFRSR retrieval is not sensitive to assumed variances (Appendix B). Other parameters $\left(C_{f}, R_{f}, C_{c}, R_{c}\right)$ are determined during retrieval. To calculate DDR, we apply available spectral values of the surface albedo at five wavelengths $(0.415,0.5,0.615,0.673,0.870 \mu \mathrm{m})$ (Michalsky et al., 2006). Also we assume that the real refractive index $n$ is equal to 1.5. The MFRSR-retrieved size distribution function and the complex refractive index are used to calculate optical properties of aerosol using Mie theory for each wavelength.

\section{Optical properties}

Figure 3 shows typical size distribution obtained from in situ aircraft data (Hallar et al., 2006) for 9 May 2003, and corresponding MFRSR-derived one. The latter coincides with in situ size distribution, except a fraction that represent large particles (geometric mean diameter is larger than $3 \mu \mathrm{m}$ ). Considerable differences for this fraction can be attributed to two main factors. First, the contribution of large particles to the variability of aerosol optical depth in the visible spectral range $(0.415,0.870 \mu \mathrm{m})$ is relatively small, thus making it difficult to determine the size distribution in the wide particle range. Second, uncertainties of in situ measurements of large particle are relatively large.

The model and retrieved $\tau$ values are in a good agreement (Fig. 4). This good agreement $(\sim 1 \%)$ is obtained even for the cases with strong vertical variability ( 9 May and 27 May), low $\tau$ (12 May), and relatively weak spectral dependence of $\tau$ (9 May). Since in situ measurements provide $\varpi_{0}$ and $g$ values at only a single wavelength $(0.55 \mu \mathrm{m})$, we estimate the AERONET values for this wavelength by using available retrievals at $0.44 \mu \mathrm{m}$ and $0.67 \mu \mathrm{m}$ and linear interpolation. To estimate the MFRSR-derived values of $\varpi_{0}$ and $g$ at $0.55 \mu \mathrm{m}$, a similar interpolation is performed for the MFRSR retrievals at $0.5 \mu \mathrm{m}$ and $0.673 \mu \mathrm{m}$. The MFRSR-retrieved values of $\varpi_{0}$ and $g$ are consistent with independent retrievals (Fig. 5). For example, the relative difference between in situ and MFRSR 

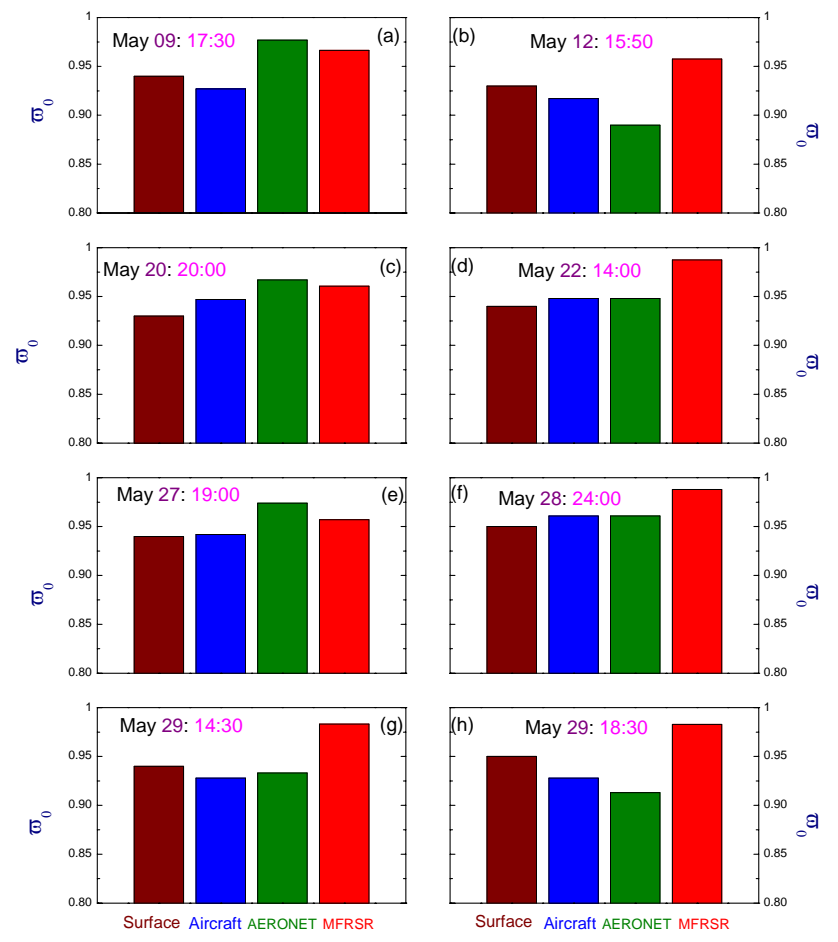

Fig. 5. Single-scattering albedo $\left(\varpi_{0}\right)$ derived from the in situ surface (brown), aircraft (blue), AERONET (green) and MFRSR (red) data at $0.55 \mu \mathrm{m}$ wavelength.

values is about $3 \%$. Very close agreement between in situ surface and aircraft retrievals may appear surprising especially for cases with strong vertical variability (e.g., 27 May). This variability is most likely associated with the bulk variability in extensive properties such as the extinction coefficient, while intensive aerosol properties $\left(\varpi_{0}, g\right)$ show less variability with altitude.

Figure 6 illustrates the comparison for the retrieved $g$ values. Similar to $\varpi_{0}, g$ values obtained from the in situ surface and aircraft measurements coincide closely: these values are in the range from 0.55 to 0.65 and represent typical values for dry aerosol (Andrews et al., 2006). The MFRSR-retrieved values of $g$ are larger $(0.65 \pm 0.03)$ than those obtained from the in situ retrievals $(0.6 \pm 0.05)$. Such differences can reach $10 \%$ for a case with low $\tau$ (12 May). However, the MFRSRretrieved $g$ values are similar to the AOS-derived $g$ values $(0.65 \pm 0.05)$ obtained at ambient conditions (Andrews et al., 2006). There is reasonable agreement between the MFRSR $(0.65 \pm 0.03)$ and AERONET retrievals $(0.67 \pm 0.04)$ for the majority of cases (Fig. 6).

Sampling issues, temporal difference between measurements (Table 2), and the vertical stratification of aerosol may be responsible for some of the differences between various methods of determining $g$. It should be mentioned, that none of these methods provide actual determination of the asymmetry parameter. For example, in situ derived values
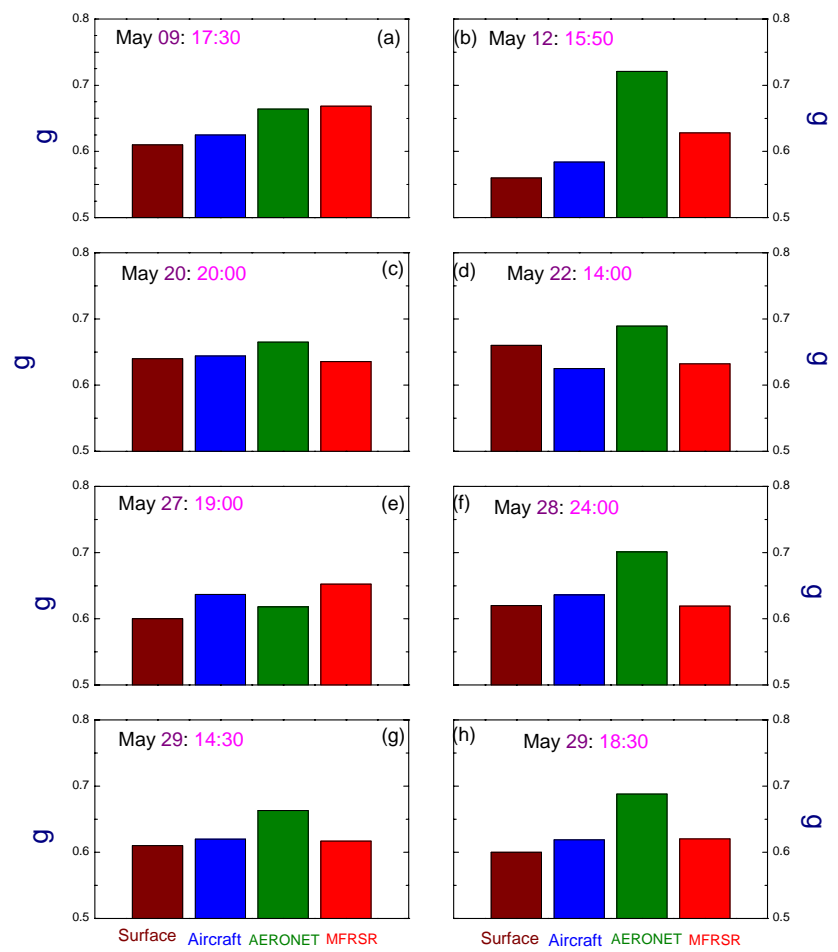

Fig. 6. The asymmetry parameter $(g)$ derived from the in situ surface (brown), aircraft (blue), AERONET (green) and MFRSR (red) data at $0.55 \mu \mathrm{m}$ wavelength.

of $g$ (both surface and aircraft) are obtained using measured backscattering fraction and the parameterization (Wiscombe and Grams, 1976), while AERONET and MFRSR derived values of $g$ are obtained using the remote sensing instruments (CIMEL and MFRSR), different data inversion techniques, and different samplings. The MFRSR retrieval uses the diffuse irradiance (from hemispherical observations), whereas the AERONET retrieval applies the sky-radiances (from solar almucantar scans during lower sun elevation angles and from the principal plane scans during higher sun elevation angles). In contrast to the AERONET sampling of diffuse radiation (sky scanning), the MFRSR sampling (hemispherical) is independent of the solar zenith angle. Kassianov et al. (2005) discussed differences between the AERONET and MFRSR retrievals. Also, Kassianov et al. (2005) demonstrated that uncertainties in input data (e.g., real refractive index) affect only slightly the MFRSR-retrieved intensive aerosol properties $(\leq 10 \%)$ and the diffuse surface irradiances $(\sim 1 \%)$. The latter is due to compensation effects of $\varpi_{0}$ and $g$ (e.g., overestimation of $\varpi_{0}$ is compensated by underestimation of $g$ ). 

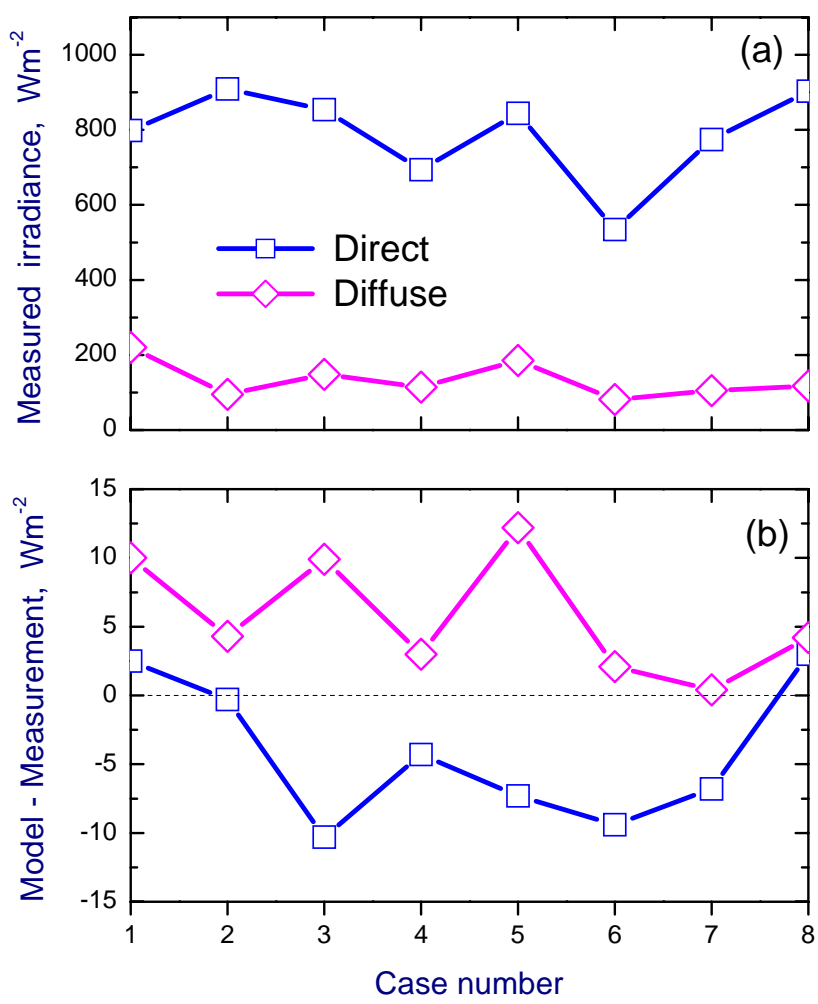

Fig. 7. (a) Measured direct and diffuse irradiances and (b) the corresponding differences (model-measurements) of direct and diffuse irradiances as function of case number.

\section{Radiative closure}

To further validate the MFRSR retrieval, we consider a quantitative comparison that is called a closure experiment (e.g., Michalsky et al., 2006; Ricchiazzi et al., 2006). In such an experiment, the measured value of a dependent variable (e.g., the diffuse irradiance) is compared to the value that is calculated from measured/retrieved values of the independent variables (e.g., aerosol optical properties, surface albedo). The outcome of a closure experiment provides a direct evaluation of the combined uncertainty of the radiative transfer (RT) model and measurements/retrievals. Close agreement between measured and calculated results demonstrates that the RT model and measurements/retrievals may be a suitable representation of the observed system.

Closure experiments have been successfully conducted at the ACRF North Slope of Alaska site (Barnard and Powell, 2002) and more recently at the Southern Great Plains (SGP) site (Michalsky et al., 2006). However, prior to these successes obtaining reasonable agreement between model and measured diffuse irradiances at the surface was a longstanding problem; in particular, the model results substantially overestimated the diffuse measurements (e.g., Kato et al., 1997; Halthore et al., 1998). The success of the recent closure experiments (Barnard and Powell, 2002; Michalsky et al., 2006) over a wide range of aerosol cases is attributed to (i) better specification of input parameters $\left(\tau, \varpi_{0}, g\right.$, surface albedo) and (ii) more accurate observations of the diffuse irradiance than in previous studies.

Similar to Michalsky et al. (2006), we perform the radiative closure for the broadband direct and diffuse irradiances by using the MFRSR-derived aerosol optical properties and the remaining input parameters (e.g., surface albedo, water vapor). The latter are taken from (Michalsky et al., 2006). Figure 7 shows results of the radiative closure. For both direct and diffuse components, the difference between model calculations and observations is within $5 \mathrm{~W} / \mathrm{m}^{2}$ for most of the cases. This difference is comparable with measurement uncertainties (Michalsky et al., 2006). The largest difference $\left(\sim 12 \mathrm{~W} / \mathrm{m}^{2}\right)$ is obtained for 27 May (case 5), and a similarly large difference was obtained by Michalsky et al. (2006) for this case. The most likely cause is a small error in the determination of $\tau$. Michalsky et al. (2006) have shown that the agreement between the model and measured irradiances can be brought into very good agreement by changing $\tau$ by 0.01 . This magnitude is the estimated uncertainty of $\tau$ derived from well-calibrated measurements (Michalsky et al., 2001). Figure 7 also reveals that, in general, for the majority of cases the differences between the model and measured irradiances have similar absolute values for both the direct and diffuse irradiances. The total (direct plus diffuse) fluxes obtained from model calculations and measurements are in very good agreement $\left(\sim 5 \mathrm{~W} / \mathrm{m}^{2}\right)$ in all cases, except case \#1 $\left(\sim 15 \mathrm{~W} / \mathrm{m}^{2}\right)$. Note that for this case, the MFRSR-derived $\tau$ is smaller than the NIMFR-derived $\tau$ and the difference between them is about 0.01 (Appendix A). Increasing $\tau$ by 0.01 produces about $5 \mathrm{~W} / \mathrm{m}^{2}$ decrease in model direct flux and good agreement $\left(\sim 5 \mathrm{~W} / \mathrm{m}^{2}\right)$ between total model and total measured irradiances (Appendix A).

\section{Summary}

We have introduced an updated version of our retrieval technique (Kassianov et al., 2005) that uses the MFRSR measurements and makes possible a simultaneous retrieval of the single-scattering albedo $\left(\varpi_{0}\right)$ and the asymmetry parameter $(g)$ from spectral measurements of the direct irradiance and the diffuse-to-direct ratio (DDR). In comparison with the previous version, the updated version is much faster and more flexible.

Our technique requires assumptions regarding the shape of the aerosol size distribution (two-mode lognormal distributions), the variances (widths) of fine and coarse modes, the real part of the refractive index, as well as the spectral values of surface albedo. The latter can be estimated from satellite or surface measurements. Our technique includes two steps. The first step infers the aerosol size distribution. To do this, we iterate four parameters of two lognormal distributions (volume concentration and median radius of fine 
Table A1. Aerosol optical depth (AOD), single scattering albedo (SSA), asymmetry parameter (AP), direct and diffuse irradiances calculated for eight cases by using as input AOD values derived from MFRSR and NIMFR data.

\begin{tabular}{llccccccccc}
\hline Properties & AOD from & \multicolumn{10}{c}{ Case number } \\
& & 1 & 2 & 3 & 4 & 5 & 6 & 7 & 8 & $\begin{array}{l}\text { Mean } \\
\text { (all cases) }\end{array}$ \\
\hline \multirow{2}{*}{ AOD } & MFRSR & 0.274 & 0.079 & 0.186 & 0.175 & 0.261 & 0.176 & 0.123 & 0.106 & 0.173 \\
& NIMFR & 0.284 & 0.077 & 0.177 & 0.175 & 0.266 & 0.172 & 0.131 & 0.117 & 0.175 \\
SSA & MFRSR & 0.966 & 0.958 & 0.960 & 0.987 & 0.973 & 0.988 & 0.983 & 0.983 & 0.98 \\
& NIMFR & 0.923 & 0.956 & 0.972 & 0.981 & 0.957 & 0.985 & 0.953 & 0.936 & 0.96 \\
AP & MFRSR & 0.668 & 0.628 & 0.636 & 0.632 & 0.652 & 0.619 & 0.617 & 0.620 & 0.63 \\
& NIMFR & 0.694 & 0.644 & 0.648 & 0.647 & 0.660 & 0.636 & 0.648 & 0.646 & 0.65 \\
Direct & MFRSR & 800.5 & 908.7 & 843.7 & 689.7 & 836.7 & 524.6 & 777.2 & 903 & 786 \\
& NIMFR & 802.1 & 910.2 & 856.3 & 694.2 & 838.2 & 534.8 & 773.8 & 896.8 & 788 \\
Diffuse & MFRSR & 230 & 99.3 & 157.9 & 117 & 197.2 & 83.1 & 105.4 & 121.2 & 139 \\
& NIMFR & 218.3 & 96.1 & 147 & 111.5 & 192.2 & 79.4 & 102.7 & 119.1 & 133 \\
\hline
\end{tabular}

Table B1a. Single scattering albedo $(0.55 \mu \mathrm{m})$ derived from MFRSR data for eight cases and different variances of fine and coarse modes.

\begin{tabular}{ccccccccc}
\hline Variances & \multicolumn{8}{c}{ Case number } \\
& 1 & 2 & 3 & 4 & 5 & 6 & 7 & 8 \\
\hline $0.4,0.6$ & 0.960 & 0.959 & 0.947 & 0.988 & 0.972 & 0.988 & 0.980 & 0.977 \\
$0.5,0.7$ & 0.966 & 0.958 & 0.960 & 0.987 & 0.973 & 0.988 & 0.983 & 0.983 \\
$0.6,0.8$ & 0.973 & 0.946 & 0.950 & 0.987 & 0.968 & 0.989 & 0.981 & 0.984 \\
\hline
\end{tabular}

and coarse modes) to match the spectral dependence of the aerosol optical depth. The second step estimates the imaginary part of the refractive index for each wavelength. To do this, we iterate values of the imaginary refractive index (for a given size distribution) to match the spectral dependence of the DDR.

We validate our retrieval in two ways. The aerosol and radiative properties obtained during the ARM Aerosol IOP form the basis for this validation. First, the MFRSR-retrieved optical properties are compared with those obtained from independent surface, AERONET, and aircraft measurements. The MFRSR-retrieved values of $\varpi_{0}$ and $g$ are consistent with the other independent retrievals. For example, the relative difference between $\varpi_{0}$ obtained from in situ surface measurements and MFRSR values is $\sim 3 \%$. For $g$ this difference is within $10 \%$ for the case with low $\tau$ (12 May). Second, a closure experiment is used to further validate the MFRSR retrieval. Similar to Michalsky et al. (2006), we perform the radiative closure for the direct and diffuse irradiances by using the MFRSR-derived aerosol optical properties and the remaining input parameters (e.g., surface albedo, water vapor) from Michalsky et al. (2006). The calculated broadband values of the direct and diffuse fluxes are comparable $\left(\sim 5 \mathrm{~W} / \mathrm{m}^{2}\right)$ to those obtained from measurements.

The favorable agreement we find between the three types of aerosol retrievals (in situ, AERONET, and MFRSR) under a variety of conditions is encouraging and suggests that the updated version of the MFRSR retrieval has the potential for remote sensing of key aerosol types in different locations. The recent successful application of this retrieval to study the dust properties during the major Saharan dust storm of March 2006 (Slingo et al., 2006) supports this expectation.

\section{Appendix A}

Uncertainty in the MFRSR-derived $\varpi_{0}$ and $g$ could arise from errors associated with $\tau$. The MFRSR-derived aerosol optical depth, $\tau_{\text {MFRSR }}$, has an uncertainty of 0.01 and is calculated by using Beer-Lambert-Bouguer law and includes correction of Rayleigh scattering and ozone optical depth. To estimate the sensitivity of MFRSR retrieval to errors associated with $\tau$, we performed the MFRSR retrieval by using $\tau_{\text {NIMFR }}$ obtained from NIMFR data. Table A1 shows that differences between MFRSR-derived $\tau_{\text {MFRSR }}$ and NIMFRderived $\tau_{\text {NIMFR }}$ are within 0.011 . Note that NIMFR-derived values of $\tau$ are in very good agreement with those obtained from the AERONET data (Michalsky et al., 2006) and, therefore, $\tau_{\text {NIMFR }}$ can be considered as the reference. Also Table A1 demonstrates that uncertainties in $\tau$ could result in 0.045 and 0.026 changes in $\varpi_{0}$ and $g$, respectively. The corresponding differences in the broadband fluxes can be on the order of $10 \mathrm{~W} / \mathrm{m}^{2}$. However, averaged values (over all cases) 
Table B1b. Asymmetry parameter $(0.55 \mu \mathrm{m})$ derived from MFRSR data for eight cases and different variances of fine and coarse modes.

\begin{tabular}{ccccccccc}
\hline Variances & \multicolumn{8}{c}{ Case number } \\
& 1 & 2 & 3 & 4 & 5 & 6 & 7 & 8 \\
\hline $0.4,0.6$ & 0.679 & 0.625 & 0.657 & 0.638 & 0.655 & 0.625 & 0.616 & 0.623 \\
$0.5,0.7$ & 0.668 & 0.628 & 0.636 & 0.632 & 0.652 & 0.619 & 0.617 & 0.620 \\
$0.6,0.8$ & 0.668 & 0.633 & 0.641 & 0.625 & 0.650 & 0.621 & 0.619 & 0.625 \\
\hline
\end{tabular}

of both optical and radiative properties are not sensitive to uncertainties in $\tau$ (Table A1, last column).

\section{Appendix B}

Another factor that can contribute to uncertainties of the MFRSR-derived $\varpi_{0}$ and $g$ is the assumed variances for fine and coarse modes. To estimate sensitivity of the MFRSR retrieval to such assumptions, we performed the MFRSR retrieval by using three sets of variances. In the first set, variances of fine and coarse mode are specified as 0.4 and 0.6, respectively. For the second set, the variances are assumed as 0.5 (fine) and 0.7 (coarse). Finally, we define them as 0.6 (fine) and 0.8 (coarse) for the third set. Table B1 includes MFRSR-derived values of $\varpi_{0}$ and $g$ obtained for these three sets. The good agreement between these values suggests that the MFRSR retrieval is not sensitive to assumed variances for fine and coarse modes.

Acknowledgements. This work was supported by the Office of Biological and Environmental Research of the U.S. Department of Energy as part of the Atmospheric Radiation Measurement (ARM) Program. We thank M. Alexandrov, P. Kiedron, J. Michalsky, J. Ogren, P. Ricchiazzi and D. Turner for providing useful discussions and valuable suggestions. The authors are grateful to two reviewers for their helpful comments.

Edited by: S. Martin

\section{References}

Alexandrov, M., Lacis, A., Carlson, B., and Cairns, B.: Remote sensing of atmospheric aerosols and trace gases by means of multifilter rotating shadowband radiometer. Part I: Retrieval algorithm, J. Atmos. Sci., 59, 524-543, 2002.

Anderson, T. and Ogren, J.: Determining aerosol radiative properties using the TSI 3563 integrating nephelometer, Aerosol Sci. Technol., 29, 57-69, 1998.

Andrews, E., Sheridan, P., Fiebig, M., McComiskey, A., et al.: Comparison of methods for deriving aerosol asymmetry parameter, J. Geophys. Res., 111, D05S04, doi:10.1029/2004JD005734, 2006.

Andrews, E., Sheridan, P. J., Ogren, J. A., and Ferrare, R.: In situ aerosol profiles over the Southern Great Plains cloud and radiation test bed site: 1. Aerosol optical properties, J. Geophys. Res., 109, D06208, doi:10.1029/2003JD004025, 2004.
Barnard, J. and Powell, D.: A comparison between modeled and measured clear-sky radiative shortwave fluxes in Arctic environments - with special emphasis on diffuse radiation, J. Geophys. Res., 107, 4383, doi:10.1029/2001JD001442, 2002.

Baumgardner, D., Jonsson, H., Dawson, W., O'Connor, D., et al.: The cloud, aerosol and precipitation spectrometer (CAPS): A new instrument for cloud investigations, Atmos. Res., 59-60, 251-264, 2002.

Campbell, J., Hlavka, D., Welton, E., Flynn, C., et al.: Full-time eye-safe cloud and aerosol lidar observation at Atmospheric Radiation Measurement Program sites: Instruments and data processing, J. Atmos. Oceanic Technol., 19, 431-442, 2002.

Dubovik, O., Holben, B., Eck, T., Smirnov, A., et al.: Variability of absorption and optical properties of key aerosol types observed in worldwide locations, J. Atmos. Sci., 59, 590-608, 2002.

Ferrare, R., Turner, D., Clayton, M., Schmid, B., et al.: Evaluation of daytime measurements of aerosols and water vapor made by an operational Raman lidar over the Southern Great Plains, J. Geophys. Res., 111, D05S08, doi:10.1029/2005JD005836, 2006.

Fiebig, M. and Ogren, J.: Retrieval and climatology of the aerosol asymmetry parameter in the NOAA aerosol monitoring network, J. Geophys. Res., 111, D21204, doi:10.1029/2005JD006545, 2006.

Gasparini, R., Li, R., Collins, D., Ferrare, R., et al.: Application of aerosol hygroscopicity measured at the Atmospheric Radiation Measurement Program's Southern Great Plains site to examine composition and evolution, J. Geophys. Res., 111, D05S12, doi:10.1029/2004JD005448, 2006.

Gonzalez-Jorge, H. and Ogren, J.: Sensitivity of retrieved aerosol properties to assumptions in the inversion of spectral optical depth, J. Atmos. Sci., 53, 3669-3683, 1996.

Hallar, A., Strawa, A., Schmid, B., Andrews, E., et al.: Atmospheric Radiation Measurements Aerosol Intensive Operating Period: Comparison of aerosol scattering during coordinated flights, J. Geophys. Res., 111, D05S09, doi:10.1029/2005JD006250, 2006.

Halthore, R., Nemesure, S., Schwartz, S., Imre, D., et al.: Models overestimate diffuse clear-sky irradiance: A case for excess atmospheric absorption, Geophys. Res. Lett., 25, 3591-3594, 1998.

Halthore, R., Miller, M., Orgen, J., Sheridan, P., et al.: Further developments in closure experiments for surface diffuse irradiance under cloud-free skies at a continental site, Geophys. Res. Lett., 31, L07111, doi:10.1029/2003GL019102, 2004.

Hansen, J., Sato, M., and Ruedy, R.: Radiative forcing and climate response, J. Geophys. Res., 102, 6831-6864, 1997.

Harrison, L. and Michalsky, J.: Objective algorithms for the retrieval of optical depths from ground-based measurements, J. 
Appl. Opt., 22, 5126-5132, 1994.

Haywood, J. and Shine, K.: The effect of anthropogenic sulfate and soot aerosol on the clear sky planetary radiation budget, Geophys. Res. Lett., 22, 603-606, 1995.

Herman, B., Browning, R., and De Luisi, J.: Determination of the effective imaginary term of the complex refractive index of atmospheric dust by remote sensing: The diffuse-direct radiation method, J. Atmos. Sci., 32, 918-925, 1975.

Holben, B., Eck, T., Slutsker, I., Tanré, D., et al.: AERONET - A federated instrument network and data archive for aerosol characterization, Remote Sens. Environ., 66, 1-16, 1998.

Horvath, H.: Atmospheric light absorption - A review, Atmos. Environ., Part A, 27, 293-317, 1993.

Jonsson, H., Wilson, J., Brock, C., Knollenberg, R., et al.: Performance of a focused cavity aerosol spectrometer for measurements in the stratosphere of particle size in the $0.06-2.0 \mu \mathrm{m} \mathrm{di-}$ ameter range, J. Atmos. Oceanic Technol., 12(1), 115-129, 1995.

Kassianov, E., Barnard, J., and Ackerman, T.: Retrieval of aerosol microphysical properties using surface Multifilter Rotating Shadowband Radiometer (MFRSR) data: Modeling and observations, J. Geophys. Res., 110, D09201, doi:10.1029/2004JD005337, 2005.

Kato, S., Ackerman, T., Clothiaux, E., Mather, J., et al.: Uncertainties in modeled and measured clear-sky surface shortwave irradiances, J. Geophys. Res., 102, 25 881-25 898, 1997.

King, M., Byrne, D., Herman, B., and Reagan, J.: Aerosol size distributions obtained by inversion of spectral optical depth measurements, J. Atmos. Sci., 35, 2153-2167, 1978.

Long, C. and Ackerman, T.: Identification of clear skies from broadband pyranometer measurements and calculation of downwelling shortwave cloud effects, J. Geophys. Res., 105, 15 609-15626, 2000.

Meloni, D., di Sarra, A., Pace, G., and Monteleone, F.: Aerosol optical properties at Lampedusa (Central Mediterranean) - 2. Determination of single scattering albedo at two wavelengths for different aerosol types, Atmos. Chem. Phys., 6, 715-727, 2006, http://www.atmos-chem-phys.net/6/715/2006/.

Michalsky, J. J., Schlemmer, J., Berkheiser, W., Berndt, J., et al.: Multiyear measurements of aerosol optical depth in the Atmospheric Radiation Measurement and Quantitative Links programs, J. Geophys. Res., 106, 12 099-12 107, 2001.

Michalsky, J., Anderson, G., Barnard, J., Delamere, J., et al.: Shortwave radiative closure studies for clear skies during the Atmospheric Radiation Measurement 2003 Aerosol Intensive Observational Period, J. Geophys. Res., 111, D14S90, doi:10.1029/2005JD006341, 2006.

Min, Q., Joseph, E., and Duan, M.: Retrievals of thin cloud optical depth from a multifilter rotating shadowband radiometer, J. Geophys. Res., 109, D02201, doi:10.1029/2003JD003964, 2004.
Petters, J., Saxena, V., Slusser, J., Wenny, B., et al.: Aerosol single scattering albedo retrieved from measurements of surface UV irradiance and a radiative transfer model, J. Geophys. Res., 108(D9), 4288, doi:10.1029/2002JD002360, 2003.

Ricchiazzi, P., Gautier, C., Ogren, J., and Schmid, B.: A comparison of aerosol optical properties obtained from in situ measurements and retrieved from Sun and sky radiance observations during the May 2003 ARM Aerosol Intensive Observational Period, J. Geophys. Res., 111, D05S06, doi:10.1029/2005JD005863, 2006.

Russell, P., Kinne, S., and Bergstrom, R.: Aerosol climate effects: Local radiative forcing and column closure experiments, J. Geophys. Res., 102, 9397-9407, 1997.

Sheridan, P., Jefferson, A., and Ogren, J.: Spatial variability of submicrometer aerosol radiative properties over the Indian Ocean during INDOEX, J. Geophys. Res., 107, 8011, doi:10.1029/2000JD000166, 2002.

Sheridan, P., Delene, D., and Orgen, J.: Four years of continuous surface aerosol measurements from the Department of Energy's Atmospheric Radiation Measurement Program Southern Great Plains Cloud and Radiation Testbed site, J. Geophys. Res., 106, 20735-20 747, 2001.

Slingo, A., Ackerman, T., Allan, R., Kassianov, E., et al.: Observations of the impact of a major Saharan dust storm on the Earth's radiation budget, J. Geophys. Res. Lett., 33, L24817, doi:10.1029/2006GL027869, 2006.

Strawa, A., Elleman, R., Hallar, A., Covert, D., et al.: Comparison of in situ aerosol extinction and scattering coefficient measurements made during the Aerosol Intensive Operating Period, J. Geophys. Res., 111, D05S03, doi:10.1029/2005JD006056, 2006.

Strawa, A., Castaneda, R., Owano, T., Baer, D., et al.: The measurement of aerosol optical properties using continuous wave cavity ring-down techniques, J. Atmos. Ocean. Technol., 20, 454-465, 2003.

Wang, J., Christopher, S., Nair, U., Reid, J., et al.: Mesoscale modeling of Central American smoke transport to the United States: 1. "Top-down" assessment of emission strength and diurnal variation impacts, J. Geophys. Res., 111, D05S17, doi:10.1029/2005JD006416, 2006.

Wiscombe, W. and Grams, G.: The backscattered fraction in twostream approximations, J. Atmos. Sci., 33, 2440-2451, 1976.

Zhang, J., Christopher, S., Remer, L., and Kaufman, Y.: Shortwave aerosol radiative forcing over cloud-free oceans from Terra: 2. Seasonal and global distributions, J. Geophys. Res., 110, D10S24, doi:10.1029/2004JD005009, 2005. 